\title{
UNA HISTORIA
}

\section{Sobre la creación de la Facultad de Arquitectura Diseño y Urbanismo de la UNL}

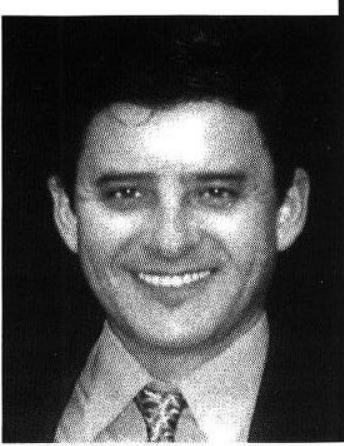

\author{
ARQ. MAREELO MOLINA \\ CONSEJERO DIRECTIVO POR LLL CLAUSTRO DOCENA'E: \\ PROFESOR TITIIAR CÁTEDRAS DE INTROILCCIÓN A LA IISTORIA Y \\ TEORÍA Y CIRITTCA DE LA ARQLITECTURA
}

El calor se pegaba al cuerpo aquella noche de diciembre de 1984. Ya era tarde cuando sonó la bocina de la "cupé" Fiat roja del "narigón" Cena que, con el "negro" Anselmi, Guillermo Diez y Miguel Rodríguez pasaron a buscar por casa al "viejo" Iván. El motivo, viajar a Buenos Aires para entrevistarse con el entonces ministro de Educación del Gobierno Nacional.

La carpa Ilevaba demasiado tiempo plantada frente al Arzobispado, las fiestas se acercaban y a las autoridades eclesiásticas les resultaba cada vez más incómodo ese grupo de estudiantes en huelga de hambre. Por otra parte, la amenaza era latente: la carpa podía darse vuelta y ubicarse al otro lado de la plaza, frente al poder político.

En febrero el calor seguía agobiante pero no nos pesaba. Salíamos de la reunión en la sala del Consejo Superior de la Universidad donde el Rector, Benjamín Stubrin, nos había solicitado presentáramos un plan de factibilidad, en recursos humanos y población estudiantil, para crear la Facultad de Arquitectura de la UNL. Éramos un grupo de docentes despedidos, otros renunciantes por solidaridad, de la UCSF; ya se sumaban también profesionales del medio con los que además compartíamos la lucha por la colegiación profesional. Todos sentíamos el desafío por delante.

El 13 de abril de 1987 éramos pocos, las autoridades de la Facultad y algunos familiares, amigos. Casi que la sala del Consejo Superior -aquella misma sala- resultaba grande. Ese día mi mujer recibía el título. Era la primera camada de egresados de la Facultad de Arquitectura de la UNL. ...Dos años.

Dos años desde aquel verano. La Facultad de Arquitectura de la UNL, funcionando en los salones del comedor universitario -escenario a su vez de otras historias de reivindicaciones-, promovía sus primeros egresados.

Mucho de la historia de la creación de esta facultad es también parte de mi historia personal, y muchos de los que todavía trajinamos las aulas tenemos algo muy personal metido en esta historia. Me asalta, en primera instancia, el imperativo académico que, desde la distancia que impone su lenguaje propio, pone a los hechos en la dimensión del objeto de estudio preservando a las personas de los olores y los sudores de los acontecimientos vividos; o el de ocupar el lugar junto a los hechos, sentir la ansiedad, tocar los recuerdos sin barnices ni envolturas analíticas. Con los riesgos que supone, siento la necesidad de andar este último camino...

En pleno Proceso y con Zaspe como Arzobispo, en lo que respecta a la Facultad de Arquitectura al menos, en la UCSF se desarrolló una particular experiencia en la que algunos docentes desplazados e inclusive perseguidos hasta el exilio, como Iván Hernándcz Larguía, encontraron un espacio de trabajo. Mucho de lo que son hoy las cátedras de historia deriva del aporte sustancial de personas de aquella época, como el nombrado, Horacio Gnemmi, Reinante, Falco que, jóvenes, acom- 
pañaron y respaldaron la labor de formación de lo que entre otras cosas fueron el entonces Instituto de Historia, los cursos de formación docente -donde iniciamos experiencias varios de los que hoy ocupamos cátedras de historia en la FADU-, los primeros proyectos de investigación que se elaboraran en esa Facultad, etc.

La formación de este grupo, a partir de compartir las experiencias, significó la lanzadera para un salto cualitativo y un cambio de dirección en el modo en el que la historia era entendida y enseñada. Sirvieron de consolidación las relaciones que estos docentes acercaron de referentes nacionales en la historia de la Arquitectura como Ramón Gutiérrez, Marina Waisman, etc., con quienes se abrieron los primeros canales de comunicación a partir de los cuales se establecieron relaciones que aún hoy se cultivan.

Un grupo de alumnos como éramos Adriana Collado, Luis Müller, José Luis Tenutta, Susana Zanón, Alfredo Stipech, Miriam Bessone, quien escribe..., formábamos parte y en ese compartir experiencias fuimos estableciendo las bases sobre las que cada uno nos afirmaríamos para desarrollar nuestra historia académica.

Un hecho que por entonces era verificable es que el área y el Instituto de historia constituian un grupo consolidado y con posición tomada, que reiteradamente era expuesta frente a las autoridades defendiendo principios como los de la construcción del saber desde la reflexión crítica y la investigación liberada de toda atadura dogmática.

En síntesis, las bases que se sentaron a partir de esta labor permitieron un cambio en el sentido de cómo se entendía y se enseñaba la historia, de la formación sistemática como parte de una acción estratégica de largo plazo, de recursos humanos integrados tempranamente al trabajo común; todo lo que le otorgó al grupo una identidad reconocible en la UCSF, lo que generó no pocos chispazos por la libertad de criterio y fidelidad a sus principios. Éstos no demorarían en manifestarse tiempo después, cuando en plena lucha por la normalización y frente al firme apoyo a los estudiantes, que fuera intensamente vivido por el grupo de docentes del área, produjeron una serie de despidos que fueron rápidamente seguidos por la renuncia solidaria de otros.

Creo importante aclarar a esta altura del relato que mi mirada tiene necesariamente un lugar y es el de mi experiencia personal en el área de Ciencias Sociales. No pretende constituirse en la Historia, simplemente quiere ser un aporte, fragmentario, a la construcción de la memoria de la creación de esta Facultad. Hoy creo que es necesario recuperar algunas de estas experiencias, hechos, acontecimientos cotidianos, muchos de ellos sostenidos por los frágiles -y fatalmente sutiles e imprecisoshilos de la memoria para que vayan adquiriendo el rango de una historia, de registro testimonial.

Hubo también otros docentes de otras áreas luchando codo a codo. De hecho, constituimos casi todos la base del plantel que avaló la creación de la FADU en el plan de factibilidad que solicitara Stubrin. Me remito, entonces, solamente al registro de mi memoria y al entorno de mi formación y del área a la que hoy sigo perteneciendo.

Se había puesto en evidencia, en los últimos años -1981, 1982 y 1983-con el reconocimiento que las producciones de alumnos de la Facultad de la UCSF obtuvieran en concursos nacionales e internacionales de estudiantes que, del mismo modo que en "el área de las Historias", algo estaba pasando en toda la Facultad. Allí también trabajaron alumnos que a partir de 1984 asumieron la misma lucha y hoy son parte del presente de la FADU.

Nuevas ideas, nuevas aspiraciones, una base de recambio de los planteles docentes que con estos antecedentes evidentemente, en el proyecto de la UCSF, no iban a tener cabida. Varios de quienes formaron parte de las experiencias de esos grupos constituyeron un núcleo fuerte de docentes en todas las áreas con el que se abrirá la nueva Facultad.

El 10 de diciembre de 1983, la restauración democrática significó la recuperación para muchos, y la adquisición inicial para otros, de los derechos de participación, representación y expresión.

En contraparte, la muerte de Zazpe, recién comenzado el ' 84 (el 24 de enero), habría de marcar un cambio importante en 
el criterio político del manejo de la Universidad por parte del Arzobispado.

Recuperaron espacio de poder sectores conservadores que habrían de imponer una fuerte subordinación a los principios confesionales, no sólo de los integrantes de la comunidad universitaria, sino del mismo conocimiento que debía quedar subordinado a un plan que se dio en llamar "Plan para la Evangelización de la Cultura". Esta suerte de regresión, opuesta al clima imperante y a las nuevas instancias abiertas en la realidad nacional, provocó que las autoridades de la UCSF tomaran ciertas decisiones políticas que precipitaron los hechos en un marco de condiciones ya maduradas y consolidadas.

Se llamó a elecciones de representantes estudiantiles frente a una demanda de normalización institucional declamando ponerse a tono del clima social y político que se vivía, pero desde una posición francamente reaccionaria a ese momento histórico con el que paradójicamente decía articularse. La consecuencia fue, obviamente, que los representantes estudiantiles elegidos no resultaron del agrado de las autoridades. Su no reconocimiento provocó el pliegue en la historia de lo que sería poco tiempo después la creación de la Facultad de Arquitectura en la UNL.

La lucha de la FAU, el momento histórico en el que se dio, se articula con otra lucha sostenida por aspiraciones idénticas, peleada por actores casi comunes, como fue la llevada adelante por la conducción del centro de Arquitectos. Después de 7 años oscuros, las aspiraciones de participar y decidir los proyectos individuales y colectivos en todos los niveles sociales, de la Universidad y Asociaciones de representación profesional en particular, permitieron encontrar acuerdos y coordinar estra-

\section{MAS VOCES SE SUMAN A LOS ALUMNOS}

\section{EN LA HUELGA DE HAMBRE}
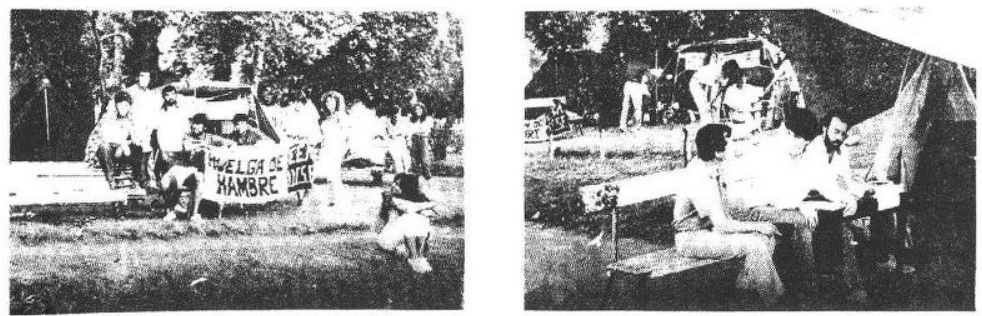

En respuesta a la cotive Catoria efectuads por el Cen Fe, ante la siruación piant: ta en in Froultad de Aras. tectua y con la presen

ce raprasentantes de

-Contro de

-Comision de Padres -Egressdose

Se analizó la grave cos. yuntura por la que atravies Conflicto suscirtaró corsecuentemente or: Nestor Cone, Migued Hosfrlguez, Merceta Sarulow y Cortos Corga (contr andiantes

Arquitectos Carlos F Garcoto Molina y Protesor an Hernandez Larguia (contes! Cinsor 8onu, Gladys 8 . wisio se Doni. Hector Chie Ghietro y Pené Caro $4 \mathrm{com}$ sion de Padrest

Arquetectus Niroing Cestigneni, Huga Storer

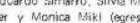

4) Solicitar una urgent se is Universicad Casolin un plazo perentorio uria st. lución al conflicto plants. El Centro de Arquite de Santa Fe, continuar tuando como entidad con cante brindando su apoyo a tod gestion tendiente a su

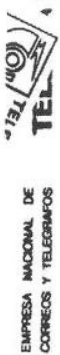

GLEGRAMA DEL PREMUO NOBEL DE LA PAZ: ESQUTVEL $84 / 12 / 371838$ ZCZC 517718 TFI 816016929 BATR STF 7015971832 TF

HEOH

URQUIIA 2943=

INEORHADOS Y PREOCUPADOS SALUD GINCO ALUMMOS EN HUELGA HAMORE

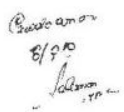

TACULTAO

ARQUITECTURA UNIVERSIOAD CATOLICA SAMTA FE RECLAMAMDO SU

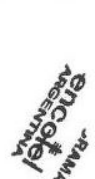

器

DEHOCRATHZACTER

NOS SOLILARIZAMOS GRUPO EN REPRESENTACION ESTUDTANTALO QUE LUCHAN PQR LDGRAR SII PARTICIPACION EN NUEVA ETAPA OEMOCRATICA UNICO CAMINO

LOGRAR

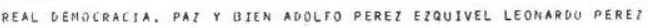

EZQUTVEL

SERVICIO PAZ Y JUSTICIA EN AMERICA LATINA

COL $29437269 /$ SANTAFESF
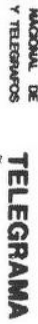

269/SANTAFESF

8 है

$\frac{3}{3}$
Adhesiones a la huelga de estudiantes (Diario El Federal, 10 de diciembre de 1984) 


\section{Su posición frente al conflicto de la UCSF fijaron docentes de Arquitectura}

Repercusión periodística del conflicto estudiantil (Diario El Litoral, Sábado 27 de octubre de 1984)

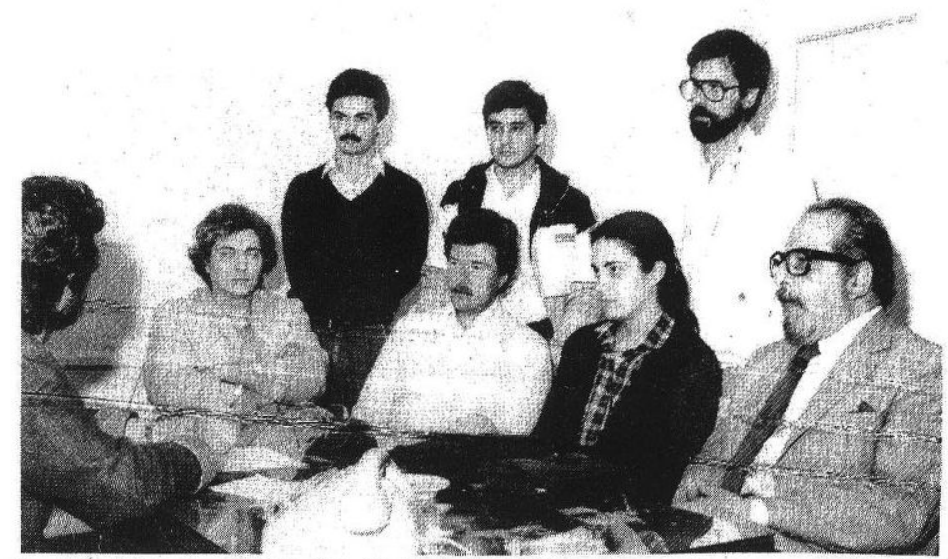

Docentes de la Facultad de Arquitectura de la UCSF dan a conocer su posición ante el conflicto que mantienen el estudiantado y la UCSF

Visitaron nuestra redacción los Arqs. Carlos Falco, Carlos Reinante, Iván Hernández Larguía, Adriana Collados, José Chiarvetti, Marcelo Molina y Miguel Irigoyen, todos docentes de la Facultad de Arquitectura de la UCSF, con el fin de sentar su posicion respecto del conflicto planteado entre autoridades $y$ alumnos de esa universidad.

En tal oportunidad, los visitantes seffalaron que este problema lleva a un grupo de profesores de dicha unidad académica a reflexionar sobre un proceso que afecta el desarrollo de las activida. des docentes y descompensa el elima de paz y comprensión necesario para promover la articulacion eficiente del ensef́ar y el aprender.

Seguidamente recordaron que el 19 de julio pp do., en una asamblea de docentes de la Facultad de Arquitectura, se aprobb́, por abrumadora mayoría, un documento en el que se impulsaba la institucionalización de la facultad y de la univerinstitucion
sidad.

Destacaron que en uno de sus párrafos se decía: "Esta vocación democratizadora no puede entenderse como un intento de precipitar una crisis que conlleve el espíritu de desarticular el fun- cionamiento de una institución, sino, por el contrario, debe ser reconocida como el legítimo derecho de los hombres libres a participar en la definición del marco institucional del lugar en que se inserta su vocación de servicio para con la comunidad".

A continuación puntualizaron también que en ese documento se expresaba que "el Episcopado argentino ha comprometido su acción pastoral en una expresa manifestación de apoyo al proceso de democratización institucional en que se encuentra empefiada la Nación".

Posteriormente hicieron hincapié en que la crisis que afecta a la UCSF es el resultado de la mora en la puesta en marcha, concreta, del proceso de institucionalización democrática.

Finalmente pusieron de resalto que condenan los excesos que han surgido en el desarrollo del conflicto, los que en nada concurren a confirmar un espíritu de respeto y comprensión indispensables para el trabajo constructivo y estimaron que el único camino, a través de cuyo recorrido se pacificarán los espírittus, es el de una normalización institucional, concretada en un plazo poco perentorio de inexcusable rapidez. tegias comunes entre personas que luchaban por lo mismo en diferentes lugares.

La lucha por la normalización que se inicia con los estudiantes de la UCSF terminará con la creación de la FADU UNL, y abre con esto espacios de participación haciendo común la lucha en los ámbitos de formación disciplinar y representación profesional. En la FADU se obtuvieron los espacios de trabajo, experimentación, desarrollo y representación que se reclamaban. En el área de Ciencias Sociales, que hoy me toca coordinar, la labor académica en el campo de la investigación, la consolidación de grupos de trabajo, transferencia, docencia, capacitación y generación de recursos humanos cada vez más calificados, exponen el camino que a partir de esta historia pudo recorrerse.

Todos los docentes que acompañaron la lucha estudiantil re- clamaron por la normalización; constituyeron la garantía inicial de un plantel sobre el que se respaldó la decisión política que la UNL, con el Rector Stubrin a la cabeza, resolvió llevar adelante a instancias de la resolución tomada por el Ministerio de Educación luego de los encuentros llevados adelante con representantes del CRUP (Consejo de Rectores de Universidades Privadas).

Como la Universidad Pública a la que pertenece, la FADU es hija también de la lucha que nace en los estudiantes y se alimenta esencialmente de las mismas aspiraciones. Su desenlace comienza a desencadenarse aquella noche calurosa de diciembre de 1984 con la que inicié mi relato.

Hoy sentí la necesidad de recordarla, no sé si por el insistente calor de este fin de marzo, o por la certeza de que a las luchas no hay que olvidarlas porque éstas, simplemente, nunca acaban. 